\title{
Creating a Vision for East Ventura, CA University, Community, and Professional Partnership
}

During fall and winter quarters BSCRP students get through the Community Planning Labs series, two studio-based courses designed to simulate a professional-like environment in responding to community-outreach projects. In 200506 one of this class sessions developed a plan for the Saticoy-Wells community in conjuction with the city of Ventura and consultants Crawford, Multary \& Clark, and relied on strong input from local residents and developers.

As part of the long-standing Cal Poly “learn by doing” tradition, the City and Regional Planning Department's Community Planning Lab (CRP 410/411 - fall and winter quarters) provides students an opportunity to work in conjunction with a local jurisdiction to create a plan for its future.

The 2005-2006 lab is working with the City of Ventura, CA to create a community plan for the Saticoy and Wells areas at the eastern edge of the City, under the direction of Professor Zeljka Pavlovich Howard and with technical assistance from Lisa Wise of Crawford Multari \& Clark Associates, a San Luis Obispo-based consulting firm that specializes in form-based codes. The code will be written by the class in conjunction with Crawford Multari \& Clark Associates.

\section{The Project}

The City of Ventura is located about 140 miles south of the City of San Luis Obispo, and its General Plan is based on the principles of Smart Growth and New Urbanism. Ventura is interested in taking the same approach in the development of the Community Plan for the Saticoy-Wells area, including a "Smart Code" to guide implementation of policies and proposals.

The Saticoy-Wells planning area, which consists of approximately 1,000 acres and has 4,700 residents, combines parts of two separate communities. Saticoy is near the eastern edge of Ventura, yet it has not been fully annexed into the city, and Wells is just north of this area and is included within the city boundary.

Within this scope, the class project had three main objectives:

(1) to provide the students with working knowledge related to the process of planning at the community scale and learn how to work with the residents, planning staff and government officials;

(2) to engage citizens in organized and proactive discussions about the future of their community;
(3) to assist the City of Ventura in implementing its recently adopted General Plan.

\section{The Process and Community Involvement}

The 2005-2006 Community Planning Lab has dedicated two academic quarters to the Saticoy-Wells Community Plan effort. As community involvement is essential to the entire planning process, the class conducted a series of workshops to present their findings and gather input from community members and developers. Initial workshops focused on getting comments about existing conditions, while later workshops were focused around comments on recommendations for the final plan.

\section{First Phase: Fall 2005}

The first phase of the planning process, conducted during the Fall Quarter of 2005, was devoted to collecting the background information needed to develop a Community Plan. This information was collected through the following studies: 1) analysis of existing land uses, housing, environmental resources, circulation, infrastructure, community facilities and services, and economic activities; 2) transect analysis and synoptic survey; and 3) assessment of the opportunities and constraints for future development in the study area.

On December, 2005 the outcome of this research was presented in a community meeting which attracted 157 people, including both residents and developers. The class presented the findings on the existing conditions in the area, and coordinated roundtable discussions to get feedback from participants. The class learned about initial plans from developers and listened to the concerns of residents. Also, a questionnaire was administered to residents to find out their expectations and concerns, and where they go for services such as medical care, groceries, clothing, and school. Results were summarized and interpreted into concerns, opportunities, and planning priorities. The outcome of this phase was assembled into a draft report on existing conditions in the Saticoy-Wells planning area. 


\section{Second Phase: Winter 2006}

The second phase is currently being conducted during the Winter Quarter as the class focused its efforts on formulating the Community Plan. The work is based on the research from the previous quarter, input from community workshops, and feedback from the Community Development Department staff. To date, two community workshops have been conducted during the present second planning phase.

During the first workshop of the current phase, held on January 27, 2006, the class presented their findings from

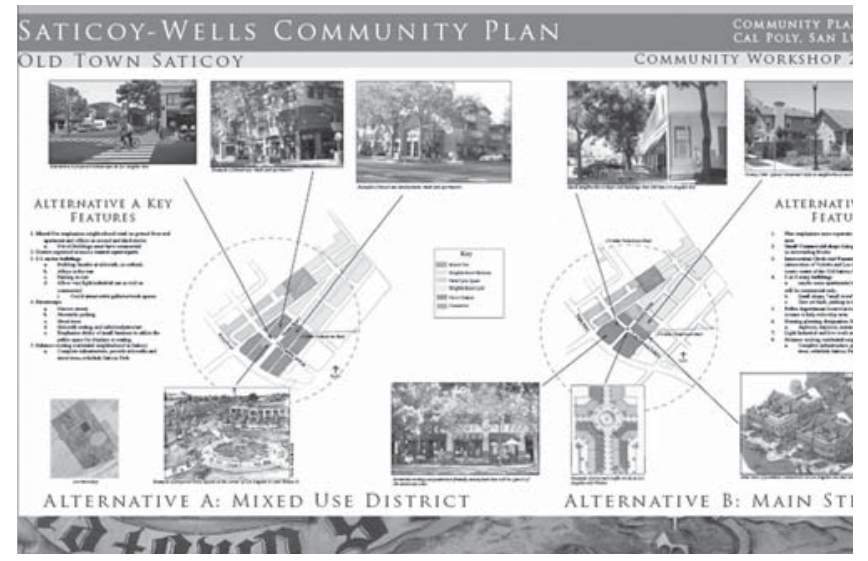

Figure 1: A community workshop in the project area. the December workshop, and conducted a visual preference survey with residents. In this survey, residents were asked to rank images of different design types (residential and commercial environments, parks, and streets) according to what they would like to see developed in their community. Students also administered the questionnaire from the previous workshop to increase the number or responses. Results from both workshops were compiled into a report on the needs and expectations of residents.

In the second workshop of the present phase, held on February 11, 2006, the focus was on formulating alternative concept plans. The class presented the findings from the previous workshops as well as the recommendations for a concept plan, including several alternatives. Developers posted current plans for their sites and spoke with students and community members about their alternatives. Then, in roundtable discussions, students obtained feedback from residents about their alternatives and the developers' plans in order to create a preferred alternative. Discussions also focused on assessing impacts on the environment and the surrounding communities, as well as on the allocation of jobs, housing, circulation, and infrastructure.

The findings, community input, and final concept plan were presented by the class at a City Council meeting on February 27,2006 . The class is now processing the comments from

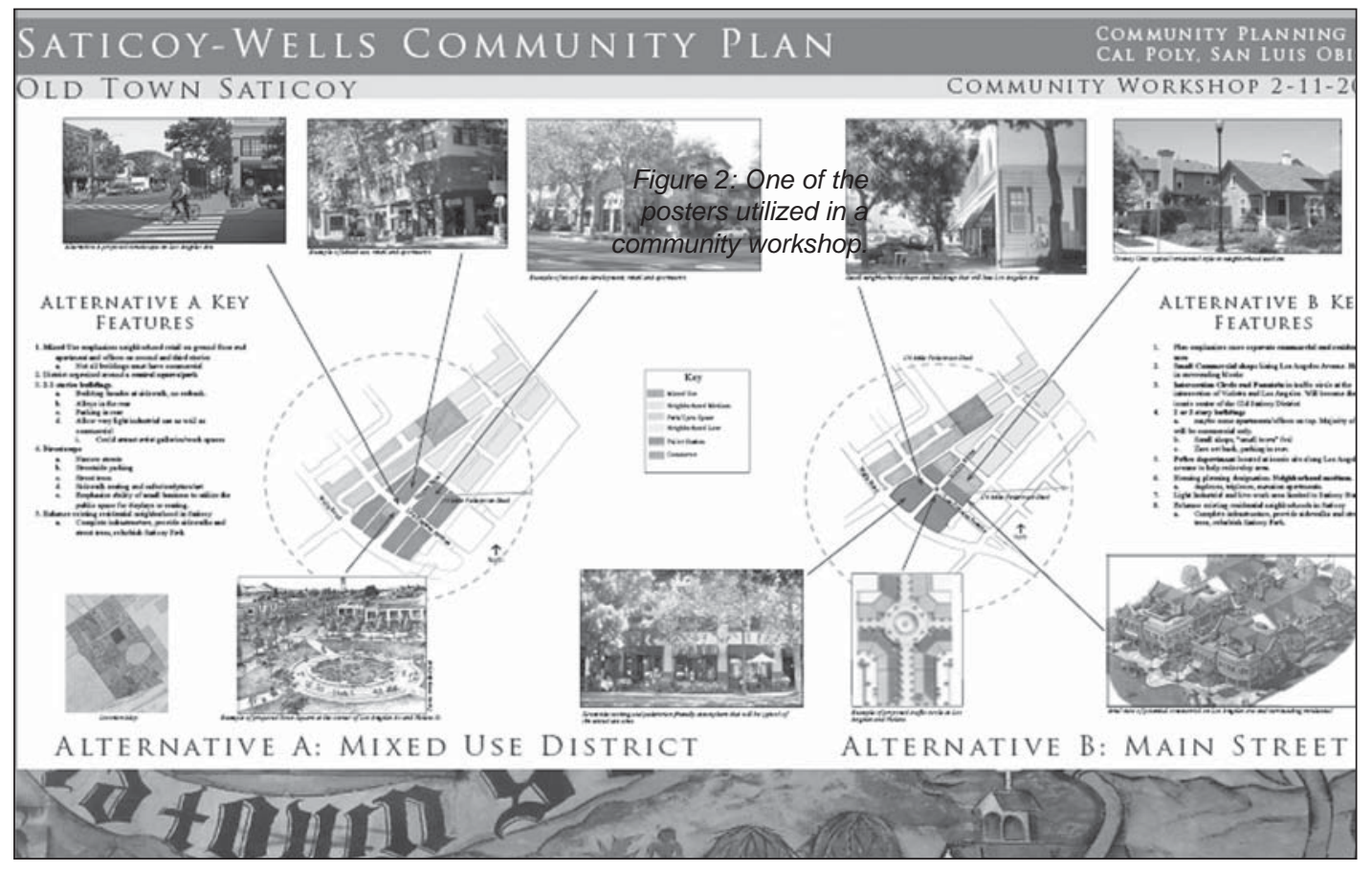


this meeting and preparing a draft Community Plan for the Saticoy-Wells planning area and development codes for selected sub-areas. Crawford Multari \& Clark Associates will take this information, prepare a final administrative draft of the Community Plan, and create the SmartCode.

\section{The Community Plan}

The process allowed the definition of three major goals to guide the development of the Saticoy-Wells Community Plan. These goals are: 1 ) to maintain and preserve the natural resources, view sheds, and agricultural heritage of the community for future generations; 2) to enhance the familyoriented community character and historical aspects, while improving public safety, transportation, and educational opportunities; and 3) to create diverse housing while improving upon civic and recreational opportunities in order to foster physical consistency throughout the community and to soften edges and buffers.

The Community Plan now being developed focuses on intensifying development throughout the area while also preserving its rich agricultural heritage. The application of appropriate smart growth concepts and new-urbanist transect zones has guided plan development and will foster a controlled transition from urban to agricultural environments. It will also generate well-defined neighborhoods and centers.

Equal consideration has been made for pedestrians, bicyclists, transit riders, and the automobile when planning for the circulation system throughout the study area. A system of pedestrian and bicycle paths (nicknamed the "green link") was proposed along the two barrancas and the Santa Clara River. This system will connect public places to neighborhoods, and will allow for alternative means of transportation. The Ventura County Transportation Commission (VCTC) has expressed interest in continuing a light rail system along the tracks which run through the study area. Surrounding the historic rail depot, the class proposed a transit-oriented development, Saticoy Station, to be connected to the green link and to an integrated and rerouted bus service.

\section{What Students Have Learned}

This is the farthest along any community plan has gone in CRP's Community Planning Lab series, and hopefully this plan will set the precedent for future projects. In this series, students traditionally work with city agencies and members of the community, and combine their needs and desires into their pedagogical exercise. However, in this project for Ventura, students also had the opportunity to work with the consulting firm Crawford Multari \& Clark Associates, which has contributed enormously in adding a professional edge to the process.

Overall, the class has had a valuable experience working with the City of Ventura, the consulting firm, residents, and developers. Students advanced in their knowledge of the planning process and have learned how to collaborate with multiple stakeholders. Every student had an opportunity to facilitate table discussions with residents and take a leading role in working with focused areas within Saticoy-Wells.

While not every student will have the same experience or gain the same skills, they will all leave this lab series much more prepared for the professional practice after graduation. Also, several students have gathered contact information for potential employers or at least contacts for their professional career. Along with showing potential employers a copy of their Community Plan, students will be able to mention that their plan has been adopted by the city and will have a lasting impact on this community. This Community Plan will influence the future the Saticoy-Wells community, and will remain in the hearts and minds of these students as a constant reminder of the skills they have learned and the great potential there is for change in this world.

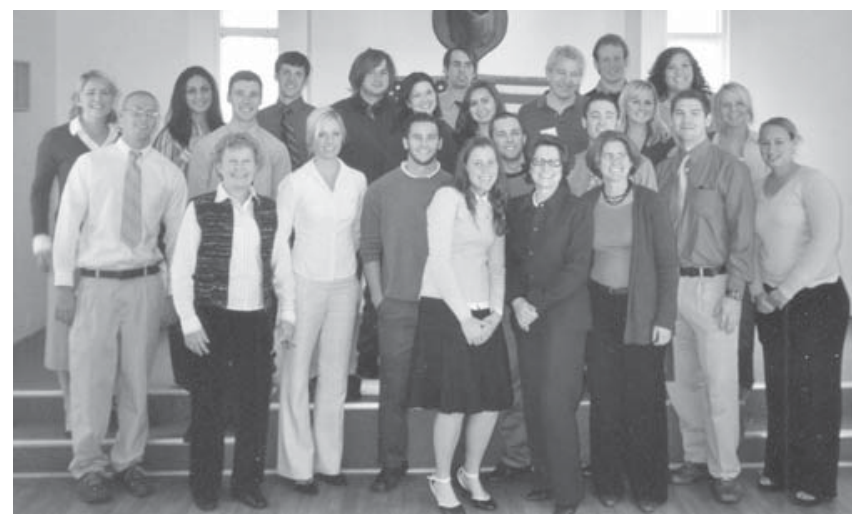

Figure 3: The class, the instructors, and the Ventura community development director Susan Dulugung after the presentation to the city council. 